\title{
CONFLITOS DE PRESSUPOSTOS NA ANTROPOLOGIA DA ARTE Relaçóes entre pessoas, coisas e imagens
}

\section{Pedro Cesarino}

Universidade de São Paulo (USP), São Paulo - SP, Brasil. E-mail: pncesarino@usp.br

DOI: http//dx.doi.org/10.17666/329306/2017

\section{Coleçóes e exibiçóes em retrospectiva}

As relações entre arte e antropologia são antigas e ainda hoje marcadas por diversos dilemas conceituais, muitos dos quais referentes à própria categoria "arte" e dois de seus pressupostos fundamentais: a noção de objeto e de sujeito criador. ${ }^{1}$ Essas relaçóes remontam tanto à formação da antropologia como disciplina científica quanto à constituição das imagens de distinção do Ocidente moderno com relação às outras sociedades. Para que seja possível detalhar a problematização desses pressupostos, é necessário recapitular alguns aspectos fundamentais - e persistentes - de tal trajetória de formação. Como se sabe, a constituição de dessas imagens é tributária de uma série de dicotomias que ainda marca a episteme ocidental,

Artigo recebido em 12/01/2016

Aprovado em 02/08/2016 como escrita/oralidade, mito/história, natureza/ cultura, simples/complexo e arte/artefato - esta última usada ao longo do século XIX para delimitar a separação entre museus de belas artes e outras instituiçôes dedicadas aos artefatos etnográficos, supostamente desprovidos de beleza e dotados apenas de função utilitária. Não tardou, porém, para que objetos provenientes das sociedades ditas primitivas fossem também elevados à categoria da arte por conta de projeçóes unilaterais de critérios de beleza e de complexidade técnica. É o caso das artes dos Maya e de civilizaçóes andinas, que eram alçadas à condição de obras de arte a partir do final do século XIX (Braun, 1993, pp. 35 ss.). Seja pelo ponto de vista científico (interessado em estudar a evoluçâo humana por meio de séries de artefatos, à maneira de Pitt-Rivers e de sua singular coleção hoje reunida em Oxford), ${ }^{2}$ seja pelo ponto de vista estético, o colecionismo ocidental era responsável não apenas por remover objetos de suas sociedades 
e contextos (como no exemplo de Griaule e Leiris em sua famosa expedição Dakar-Djibouti) ${ }^{3}$ como, também, por promovê-los a esta ou àquela categoria (arte, artefato) de acordo com seus pressupostos arbitrários. Ainda no final dos anos de 1940, o antropólogo Alfred Kroeber (1949) podia elevar determinadas peças arqueológicas (tais como as provenientes das culturas chavín, mochica e marajoara) ao panteão da história da arte por imaginar que elas se destacavam entre toda uma outra série de artefatos "inferiores", supostamente desprovidos de beleza, fluidez, expressão e outras qualidades adquiridas pelo controle técnico capaz de produzir obras-primas. Inspirado em pressupostos hegelianos, Kroeber vinculava tais obras de destaque à produção de prováveis artistas individualizados, capazes de proporcionar momentos de clímax em determinadas tradiçóes culturais sobre as quais se projetava a ideia do atraso e da inferioridade.

Ainda assim, essas mesmas apropriaçóes unilaterais das expressóes materiais alheias seriam responsáveis, a partir da segunda metade do século XIX, pelo estabelecimento de projetos institucionais e de discursos estéticos alternativos à concepção clássica de arte. Essas alternativas trariam contribuições fundamentais tanto para a reformulação da antropologia (como no caso da demolição do evolucionismo empreendida por Franz Boas, do ponto de vista teórico e expográfico ${ }^{4}$ ) quanto para o realinhamento da própria estética ocidental, que passaria a ser transformada pelas experiências modernistas. Não por acaso, o antropólogo James Clifford encontra na Paris do início do século XX um ambiente artístico e intelectual propício para a formação do que ele chamou de um "surrealismo etnográfico", ou seja, uma fragmentação e justaposição de valores culturais marcada pelo espírito crítico, pelo rebaixamento do cânone, pela desfamiliarização do real e outras subversóes da experiência para as quais a coleção heteróclita do Musée du Trocadéro e a atividade intelectual de figuras como Marcel Mauss possuíam um papel central. Nesta época, as produções materiais provenientes de sociedades ditas primitivas passavam a ocupar cada vez mais o interesse europeu, seja por suas coleçôes exibidas em posições de destaque, seja pelas fontes etnográficas fornecidas por Mauss, Métraux e outros, que seriam aproveitadas por artistas e pensadores como Georges Bataille. "Essas possibilidades", escreve Clifford, "baseavam-se em algo mais do que um velho 'orientalismo'; elas requeriam a etnografia moderna” (1988, pp. 124-125), ou seja, uma etnografia distinta da técnica de pesquisa empírica que serviu de base à etnologia francesa, à antropologia social britânica e à antropologia cultural norte-americana.

O surrealismo etnográfico se aproximaria de procedimentos comuns tanto à antropologia quanto às artes ocidentais do século XX: a desfamiliarização e o estranhamento, produzidos pelo trabalho de campo em outras sociedades e pelas perambulações surrealistas na cidade. Tal espírito, aliás, contaminaria o próprio Claude Lévi-Strauss, que dizia ter encontrado em Max Ernst a capacidade de revelar a "estranheza recíproca" dos fragmentos, no caso dos mitos ameríndios estudados pelo antropólogo nas Mitológicas. ${ }^{5}$ Ainda assim, mesmo o surrealismo etnográfico não se mostrava completamente suficiente para desarmar as projeçóes estéticas e as replicaçôes de dicotomias que persistiam na prática e nos estudos artísticos. A despeito de sua originalidade e potencial atualidade, muitas das formas de apropriação dos referenciais não ocidentais realizadas por artistas modernos levavam mais ao estabelecimento de analogias formais e à criação de mitologias individuais ou nacionais (notável em casos diversos como os de Joseph Albers, Joaquín Torres-García, Constantin Brancusi ou Alberto Giacometti) do que a um estudo efetivo dos horizontes intelectuais e estéticos alheios. As apropriaçóes e as invençôes modernistas do Outro (e de seus objetos) não estavam, portanto, exatamente voltadas para desarmar as referidas dicotomias, mesmo que tentassem conferir status positivo ao "primitivo" em suas estéticas e anseios de transgressão.

Tampouco as exibições e as instituições de arte conseguiriam superá-las ao longo do século XX, apesar de esforços diversos e sempre submetidos a polêmicas, feito as que envolveram exposiçóes como Magiciens de la Terre (Paris, Centre Georges Pompidou, 1989, curada por Jean-Hubert Martin), Primitivism in 20th Century Art: Affinity of the Modern and the Tribal (Nova York, MoMA, 1984, curada por William Rubin) e Art and Artifact (Bu- 
ffalo Museum of Science, 1989, curada por Susan Vogel), entre outras. ${ }^{6}$ Basta, para tanto, recorrer também à trajetória de passagem do Musée de l'Homme ao Musée du quai Branly, marcada pela sucessão do paradigma científico e acadêmico por outro estético e espetacular. Apesar de ainda abrigar setores de pesquisa em etnologia, o Musée Branly atribui novamente valor aurático às "obras-primas" náo ocidentais, antes submetidas ao olhar classificatório científico e, agora, selecionadas e marcadas pela encenação exótica de um primitivo de apelo turístico (então chamado de "primeiro") e bastante distinto, portanto, daquele inventado pelos primitivistas modernos em seu desejo de ruptura e transgressão. O Branly tipifica de maneira bastante clara, também, ao menos outros dois pressupostos com os quais a antropologia vem se debatendo nos últimos tempos: a transferência da categoria "arte" para regimes de pensamento alheios e a imposição de um programa estético voltado para o destaque de objetos (De L'Estoile, 2007).

Essa trajetória do colecionismo e das exibições, aqui brevemente condensada, torna notável a tenacidade dos pressupostos ontológicos modernos e seu poder de captura e de recategorização das coisas e modos expressivos alheios. Um desses pressupostos, já mencionado no caso de Kroeber, está assentado na construção do artista individual (e mutatis mutandis na própria noção de indivíduo), que seria responsável por se destacar de seu meio cultural via sua maestria técnica e elevação criativa e/ou espiritual. Não é por acaso que a exposição Magiciens de la Terre, na tentativa de oferecer um contraponto a tal pressuposto, terminava por prolongá-lo e redefini-lo pela noção dos "magos" da terra, como considera o curador Pablo Lafuente: "a agência do artista, para escapar das problemáticas do modernismo e de sua determinação sociocultural, é reformulada como a agência do mago - aquele indivíduo que estabelece uma relação privilegiada com um grupo e com um local e que, graças a tal privilégio, conquista a sua individualidade" (Lafuente, 2013, p. 16). Ao revisar as diversas críticas já realizadas à exposição, o historiador da arte Thierry Dufrêne, por sua vez, terminou por considerar a Magiciens de la Terre nos seguintes termos: "a exposição [...] deu origem a um 'imbróglio' do qual ainda não saímos, e penso que esse 'imbróglio' [...] é o que chamo de um 'mal-entendido produtivo'” (2012, p. 114). Sem mencionar diretamente o que, na antropologia contemporânea, se entende por tal expressão conceitual fundamental, Dufrêne imagina que o mal-entendido produzido pela Magiciens foi responsável por "embaralhar as fronteiras entre o museu de etnografia e o museu de arte contemporânea, tornando possível assim a criação do Museu do quai Branly" (Idem, p. 115) e sinalizando uma série de utilizaçôes ainda recentes, mesmo após a conhecida crítica de Hal Foster em The return of the real, da figura do artista-etnógrafo capaz de "questionar o seu próprio universo cultural” (Idem, p. 116). Esse movimento de retomada da aproximação entre antropologia e arte corresponderia, pois, a uma nova edição do mal-entendido produtivo que, ainda de acordo com Dufrêne, "teve por resultado que, agora [...], um objeto etnográfico e um objeto artístico surgem como as duas faces conjugadas de uma realidade cultural" (Idem, p. 118). Vemos aí como a separação entre categorias de objetos não foi desfeita, mas, mais uma vez, reconfigurada em nova solução produzida apenas por um dos lados de tal (supostamente única?) realidade cultural.

Dufrêne indica, ainda, um campo de confluência entre a antropologia e a história da arte, ao sinalizar uma partilha de procedimentos marcada pela produção de autores como Michael Baxandall. Essa partilha consistiria em considerar o "objeto de arte não apenas como um signo em uma comunicação entre produtor e consumidor/espectador, mas como um objeto composto de intencionalidades múltiplas produzido e utilizado no seio de relaçóes sociais complexas" (Idem, p. 119). Em uma perspectiva mais crítica da trajetória "estetizante" em que se inserem exposiçóes e instituiçóes como a Magiciens e o Museu do quai Branly, Lafuente prevê a possibilidade de uma antropologia capaz de "pensar objetos como dotados de sua própria agência, no mesmo nível daquela dos artistas e dos curadores, abrindo assim caminho para outra categoria de exibiçôes nas quais objetos não sejam nem determinados pelo contexto e nem descontextualizados: nas quais objetos possam fazer e desfazer relaçóes, incluindo relaçóes com o sistema que os torna possíveis" (Idem, 20). Muito embora Lafuente pareça 
se aproximar das consideraçóes de Gell, sobre as quais falaremos em seguida, vemos persistir outro pressuposto tenaz: aquele do próprio objeto como entidade basilar do sistema das artes visuais, passível ou não de ter a sua agência ou intencionalidade reconhecidas. Marcado como foco de matrizes estéticas ou reconfigurado por uma visada crítica e relacional, ele, o objeto, de toda forma permanece como algo que jaz ali, jogado adiante do sujeito, com quem estabelece uma relação tensa.

Não se trata de insinuar algum erro ou impertinência desses pressupostos, como se tal fosse uma questão plausível. Afinal, poderíamos definir a própria noção de ontologia como o conjunto de pressupostos sobre o que existe, ainda que passíveis de se submeterem a ajustes, transformações e acordos pragmáticos, como sugeriu recentemente Mauro Almeida (2013, p. 9). Trata-se, no entanto, de desenvolver uma reflexão antropológica marcada pela desestabilização permanente de tais assunçóes sobre o que existe ou, antes, pela variação especulativa em torno de múltiplas possibilidades de existência (justamente aquelas eclipsadas ou cobiçadas pelo colonialismo) para as quais entidades, tais como "objetos" e "indivíduos", talvez não sejam pertinentes ou, ao menos, não da mesma maneira como são em geral pensadas e repensadas por intelectuais ocidentais. Esta seria, então, como se verá, a diferença constitutiva entre a reflexão aqui proposta e aquele encontro entre a antropologia e a história da arte imaginado por Dufrêne: análises de desentendimentos produtivos ou de equivocidades tradutórias, como as realizadas e pensadas por autores como Marshall Sahlins $(1981,1995)$ e Eduardo Viveiros de Castro (2002, 2004), só se tornam possíveis quando suspendemos pressupostos e pontos de partida, a fim de produzir uma experiência de pensamento em torno da variação de modos de existência. Dessa forma, deixa de fazer sentido uma antropologia $d a$ arte centrada, por exemplo, na cisão sujeito/objeto e suas transformaçôes; não seria o caso, mais ainda, de mobilizar a reflexão antropológica para um fim determinado, ou seja, a arte e suas transformaçóes contemporâneas. A reflexão antropológica partiria, antes, de tal tarefa mediadora (Wagner, 1981) para construir um outro campo de complexidade.

\section{As críticas do estetismo}

A propósito da inclusão de uma rede de caça azande em uma exposiçáo de arte curada pela africanista Susan Vogel (Art/Artifact), o antropólogo Alfred Gell mostrava como o filósofo Arthur Danto ainda estava impregnado de pressupostos hegelianos ao estabelecer uma distinção entre arte e artefato. Para sustentar seu argumento em favor de tal distinçáo, Danto se ancorava no grau maior ou menor de retenção de significado por parte de um determinado objeto (produzido pelos sábios da tribo, análogos aos nossos artistas e intelectuais), que seria considerado capaz de ultrapassar o mero emprego cotidiano e atingir certa universalidade característica da obra de arte. Ao contrário de Danto, para Gell não serão exatamente o significado e a expressão do espírito absoluto aquilo que transforma algo em arte - critérios marcados por uma estetização etnocêntrica similar àquela realizada por Kroeber e tantos outros. Uma obra de arte (seja ela uma rede ou uma instalação de Rebecca Horn) será, então, algo capaz de evocar "intencionalidades complexas" (Gell, 1999, p. 211). Dessa forma, Gell se vale da dissolução da essência distintiva do objeto artístico, que já havia sido realizada por Marcel Duchamp, a fim de descartar o pressuposto estético, mas, ainda assim, mantendo um sentido possível da noção de arte para a antropologia.

$\mathrm{O}$ autor estende esse mesmo tipo de crítica para outros estudos, nos quais a presunção de significado assim como a própria validade da "arte" como categoria transcultural assentada em sua suposta superioridade espiritual - é abandonada em favor de uma análise de sua eficácia técnica. O papel da técnica já se fazia presente na reflexão sobre a habilidade (skill) elaborada por Franz Boas no clássico Primitive art, mas, com Gell, ela passa a ser evocada em paralelo com as operaçooes mágicas. A eficácia estaria na produção de uma guerra psicológica, pela qual o espectador permanece em posiçáo assimétrica com relaçâo à agência extraordinária do produtor de objetos complexos. De fato, essa mesma mobilização de índices materiais como receptáculos de agências e, dessa forma, como mediadores de redes de intencionalidades, será explorada de maneira mais aprofundada em Art and agency. Nesta obra póstuma editada em 
1998, Gell apresentava os contornos teóricos necessários para distinguir a antropologia dos aportes de outras disciplinas que a determinaram nas décadas anteriores (como no caso da influência da história da arte em Boas via a noção de Kunstwöllen de Aloïs Riegl $^{8}$ ou, mais tarde, dos pressupostos da semiologia nos estudos antropológicos sobre arte dos anos de 1960 e seguintes ${ }^{9}$ ). A especificidade antropológica estaria, de acordo com Gell, no estudo das relaçóes sociais. Dessa forma, tornava-se possível vincular sua teoria à tradição maussiana e considerar objetos de arte (não apenas os de sociedades tradicionais, vale frisar) como pessoas envolvidas em uma rede de relaçóes - mas desde que se considerasse "pessoa" com base em processos de relativização radical que a noção sofreu pela reflexão antropológica, mais capaz de lidar com teorias alternativas do que a tradição filosófica contemporânea. $\mathrm{O}$ problema antropológico para a arte seria, assim, o de identificar os processos pelos quais abduçóes de agência se estabelecem por intermédio de índices materiais capazes de produzir relaçóes assimétricas entre produtores e recipientes, suficientemente potentes para capturar pessoas em relaçóes sociais. Assim, Art and agency oferece uma perspectiva alternativa para a antropologia da arte, que deixa de ser um estudo voltado exclusivamente para as produções de sociedades não ocidentais.

Gell oferece, ainda, uma solução para o problema da divisão entre interior (mente) e exterior (mundo) que estrutura a noção de estética moderna e sua suposta aplicabilidade transcultural. O autor já havia refutado tal espécie de pressuposto ao dizer que o impacto causado sobre um espectador por determinado índice artístico (como no exemplo da elaboração gráfica das proas de canoas utilizadas pelos viajantes do circuito do Kula) não deriva apenas ou exatamente dos efeitos cognitivos da relação entre figura e fundo, mas sim da abdução, por parte do receptor, da agência extraordinária do artista eclipsado pelo índice material (Gell, 1999, pp. 159 ss.). Em outros termos, índices materiais (classificados por Gell como "arte", mas para além do que arte implica no Ocidente) transformam-se em pessoas exatamente por sua capacidade de pressupor outras pessoas por trás de si. A suposição de uma determinada agência extraordinária responsável pela elaboração do índice é, assim, o que instaura o vínculo social entre produtores e recipientes de imagens, que não se relacionam apenas ou exatamente por meio do impacto cognitivo produzido por determinada elaboração visual sobre o receptor. Em uma direção similar ao que dirá também Strathern sobre sociedades da mesma região, percebe-se que tais produções materiais são mobilizadas, sobretudo, para a produção de pessoas e de relaçóes, e não para a manutenção de processos de reificação e suas respectivas instituiçóes, tais como museus.

Muitas das críticas dirigidas à teoria de Gell (como as de Morphy, 1994, e Layton, 1981) parecem mais preocupadas em demarcar uma diferença de base com relação ao seu programa (o abandono da premissa estética, por exemplo), bem como em estabelecer pequenos ajustes de contas, do que em apontar problemas teóricos mais profundos. Exceção, no entanto, é o argumento de James Leach em torno da noção de abdução, que produziria uma excessiva centralidade do indivíduo e da habilidade técnica, tributária de matrizes modernas e insuficiente para a compreensáo de outros modos de criatividade orientados pela colaboração:

Gell precisa de objetos dos quais as pessoas possam abduzir agência, mas, em sua teoria, essa abdução sempre será atribuída ao criador que, mediante a técnica ou a habilidade, estabelece sua influência por meio do objeto. A transcendência da conjugação vontade/intelecto ressoa a tendência euroamericana de localizar a razão ou o conhecimento na mente individual, reproduzindo, assim, o sujeito por suas operaçóes no mundo externo. Gell se baseia nessa constituição da pessoa, focada em um modo de criatividade particular. Ao fim e ao cabo, ficamos com a mente individual e suas representaçóes, e com a ideia de que os não humanos podem ser agentes apenas por vizinhança: há sujeitos reais, nomeadamente nós mesmos, e há aqueles cidadãos de segunda classe do império do Sujeito (ou seja, os objetos e seus similares) (Leach, 2007, p. 183).

$\mathrm{O}$ autor aponta para um entrave de fato presente nos primeiros capítulos de Art and agency: a divisão entre agentes primários e secundários, tributária da centralidade do Sujeito e do velho incômodo ontológico moderno com relação aos não 
humanos. Veremos como o problema, que já se fazia presente nas considerações anteriores sobre a exposição Magiciens de la Terre, também ultrapassa a teoria de Gell e suas críticas. Ainda assim, Leach curiosamente não aprofunda a contaminação notável da etnografia da Melanésia e do Pacífico nos três últimos capítulos da obra póstuma. Ali, o problema das pessoas embutidas umas nas outras, mediado por índices materiais que transcendem o estatuto de objeto inanimado, não pode ser visto apenas como uma mera projeção de premissas ocidentais. Gell parece, antes, ter sido responsável por produzir uma reflexão eclética potente, na qual a teoria semiológica (bem como sua crítica), as teorias inovadoras da mente (os homúnculos de Dennett) e os velhos pilares modernos (a habilidade e o indivíduo) se combinam de maneira mais ou menos evidente com os esboços de uma teoria etnográfica possível (do Pacífico e da Oceania) desenvolvidos não apenas por ele, mas por outros especialistas na regiāo tais como Marilyn Strathern, Roy Wagner, Suzanne Küchler, Jadran Mimica e Mark Mosko.

A recusa crítica e metodológica do "estetismo" não foi sugerida apenas por Gell. Peter Gow (apud Ingold, 1994), por exemplo, refuta a proliferação de "etnoestéticas" em estudos que tomam por pressuposta a categoria "arte" via argumentos similares. Para Gow, tais estudos importam para a antropologia problemas como a ideia de uma resposta universal a determinados estímulos sensoriais, pela qual se torna possível estabelecer critérios de distinção: caberia ao antropólogo, assim, investigar a variabilidade cultural desses critérios e comparar distintos sistemas estéticos, digamos, dos Yorubá, dos Yanomami ou dos Yolngu, via uma metateoria inventada pelo cientista social (uma posição que costuma ser defendida por autores como Howard Morphy, Robert Layton e Jeremy Coote críticos de Gell, aliás). ${ }^{10}$ Para Gow, esse projeto corresponde sobretudo à vontade ocidental de inventar uma estética para outros povos. Comparar e contrastar com vistas a produzir juízos de gosto não deveriam ser problemas metodológicos de uma reflexão antropológica. Não se trata de dizer que determinadas produçóes (por exemplo, as pinturas de areia dos Navajo) não sejam belas, capazes de produzir potência estética, de transmitir significado, mas sim que a antropologia não deveria tomar tais premissas como ponto de partida. Ela deveria, em suma, procurar pelas questóes colocadas pelos Navajo sobre suas pinturas de areia e suspender as suas próprias indagações. Isso se torna possível apenas a partir de um trabalho etnográfico intensivo, cujo resultado poderá ser capaz de fazer com que a antropologia lance uma perspectiva sobre seus problemas de origem (sobre a natureza da imagem e da representação pictórica, por exemplo), mas com a clareza de que se trata de suas questóes, e náo necessariamente das dos outros. Gow ilustra seu ponto pela explicitação de Lévi-Strauss de seu próprio partido estético logo no início de $A$ via das máscaras, sem que tal partido, no entanto, pressuponha que as conexóes por ele traçadas sejam as mesmas que preocupam os povos ameríndios.

Em uma reflexão sobre os problemas da comparação, Strathern apontava para a inexistência de alguma escala automática prévia para comparar coisas, como se uma flauta (ou uma pintura de areia) pudesse ser concebida universalmente como um objeto (e a pintura como uma figura autônoma) passível de ser deslocado, com naturalidade, para um museu ou para a página de um livro. Semelhante deslocamento só faz sentido de um ponto de vista acostumado a isolar objetos e figuras de pessoas, de modo que possam ser tratados como obras de arte. Mas e se, na Melanésia por exemplo, efígies, flautas e canoas forem pessoas ou, antes, se conectassem à composição de pessoas por meio de outros processos que aqueles responsáveis pelo seu isolamento e categorização como "cultura material", "artefato" ou "obra de arte"? Nesse caso, seria necessário adotar outra postura metodológica e epistemológica, cujo ponto essencial pode ser percebido na seguinte frase da antropóloga: "não é a maneira pela qual os antropólogos controlam as analogias que está em jogo, mas sim a maneira dos atores" ([1991] 2004, p. 76). Como, no entanto, trazê-las ao plano principal? E quais seriam as consequências dessa opção?

\section{Antropologias da imagem}

Embora Gell tenha conseguido delimitar um campo conceitual para sua antropologia da arte, outros autores têm progressivamente se afastado de tal projeto. Em um artigo recente, Philippe Descola 
também se refere aos entraves gerados pela mimetização de certo modus operandi da história da arte. As pesquisas eram até então dominadas pela "análise das funções de tais objetos, do simbolismo a eles associado, das exigências formais às quais devem responder, das evoluçóes estilísticas que sofreram, das alteraçóes de sentido que os afetam quando são deslocados de seus ambientes de origem" (2010, p. 25). Como alternativa a tais pressupostos, Descola propóe uma "antropologia da figuração", capaz de ultrapassar os problemas da arte referente a determinados contextos históricos. Para o autor, a figuração, ao contrário da arte, é "uma operação universal pela qual um objeto material qualquer é investido ostensivamente de uma 'agência' socialmente definida”. Ecoando a persistência dos pressupostos modernos aqui apontados, ele sustenta, ainda na mesma passagem, que se torna possível estudar a figuração via seus distintos modos de identificação, "isto é, das formas de organização da experiência do mundo correspondente às diversas maneiras de inferir as qualidades nos existentes e, assim, de reconhecê-los como dotados de certas aptidóes que os fariam capazes deste ou daquele tipo de ação" (Idem, p. 26) Ainda que mantenha uma base universalista, Descola se desfaz dos problemas tradicionalmente associados à antropologia da arte. Seu programa é influenciado pela teoria de Gell, mas se dirige para o estudo das variaçóes dos modos de figuração em distintos regimes ontológicos a que se dedica de maneira mais detalhada em Par-delà nature et culture (2005).

Carlo Severi, por sua vez, propóe uma antropologia da memória para superar as contradiçóes derivadas da separação entre a antropologia da arte e o estudo de tradiçóes orais. $\mathrm{O}$ autor procura em Warburg as bases teóricas para a construção de uma antropologia da memória, que termina também por ser, como a de Descola, uma antropologia da imagem. Trata-se, para Severi, de pesquisar imagens dotadas de intensidade especial, a ponto de se tornarem transmissíveis, dissemináveis e persistentes. Dessa forma, ele pretende associar sua perspectiva renovada sobre Warburg a uma investigação dos "fundamentos psicológicos de toda cultura" para, dessa maneira, entender as "operaçôes cognitivas que estão envolvidas no conjunto de práticas e téc- nicas que requerem a ordenação e o funcionamento de uma tradição específica" (2007, p. 69). Ambos os projetos apontam para essa tendência de uma antropologia da imagem que, não por acaso, tem também definido as reflexóes recentes de Hans Belting ([2001] 2011, p. 32), para quem qualquer pergunta pelo estatuto da imagem se torna insuficiente quando não considera noçôes de imagem provenientes de outras culturas, capazes de problematizar definiçôes realizadas no interior da tradição ocidental. É o aporte da antropologia que, segundo o autor, permite tornar mais complexas a compreensão das formas de relação entre imagens, corpos e mídias, estudadas em An anthropology of images. Como exemplo da importância desse aporte, Belting (Idem, pp. 32-33) se refere à influência que a persistência de fórmulas visuais no ritual de serpentes dos Pueblo exerceu sobre Warburg, assim impulsionando sua elaboração da noção de nachleben em seu estudo sobre as imagens no Renascimento (recentemente reestudado por Didi-Huberman, 2002).

Mas isso ainda não seria suficiente para esgotar o problema anunciado por Marilyn Strathern, ou seja, de uma etnografia que leve às últimas consequências os pressupostos de pensamento ou as analogias mobilizadas pelos próprios atores. $\mathrm{O}$ que ocorre, mais especificamente, é que a concepção de etnografia não é mobilizada da mesma maneira por distintos projetos intelectuais que, ademais, não se interessam em desenvolver com mais radicalidade uma autocrítica epistemológica. Sem estabelecer grandes pesquisas sobre potenciais teorias nativas, Warburg na realidade estava, em $O$ ritual da serpente (2003 [1923]), interessado na maneira pela qual a iconografia e os rituais da serpente entre os Pueblo impulsionavam suas reflexóes sobre a sobrevivência das imagens. Belting, por sua vez, permanece em referências genéricas e pouco se engaja em leituras mais aprofundadas de etnografias que efetivamente levariam ao desenvolvimento de seus objetivos teóricos anunciados. As propostas de Severi e de Descola, por fim, examinam operaçôes cognitivas universais via um amplo conhecimento da etnografia, mas não exatamente de uma conexão simétrica com outros critérios de pensamento. A diferença entre esses procedimentos e outros mais preocupados com a simetria está, como diz 
Eduardo Viveiros de Castro, em imaginar "uma nova antropologia do conceito [...] que contra-efetua um novo conceito de antropologia, a partir do qual a descrição das condiçóes de autodeterminação ontológica dos coletivos estudados prevalece absolutamente sobre a redução do pensamento humano (e não humano) a um dispositivo de recognição: classificação, predicação, juízo, representação [...]" (2009, p. 7). Tal antropologia deve realizar algo que parece levar ainda mais adiante as sugestôes apontadas por Gow: um trabalho de "ontografia” (Holbraad, 2003), ou seja, um levantamento das condiçóes de possibilidade de um mundo outro e de seus conceitos, entre os quais aqueles envolvidos em suas formas expressivas. O desafio é similar ao encontrado nas seguintes palavras de Bruno Latour: "de toda forma, se eles [os cientistas sociais] querem propor uma metafísica alternativa, eles precisam primeiro se engajar na fabricação de mundos de quem estudam" (2007, p. 57).

Autores diversos (entre os quais o próprio Latour) admitem que a antropologia tem se destacado entre outras disciplinas em sua tarefa de compreensão de outros mundos possíveis e dos problemas de conexão tradutória daí derivados. Outros, como W. J. T. Mitchell, oferecem reflexóes que recuperam modos de relação com a imagem tradicionalmente estudados por antropólogos. Não por acaso, Mitchell (2005, p. 6n) reconhece, em um livro recente, sua afinidade com o pensamento de Gell ao tratar da vitalidade das imagens. Na mesma obra, o autor diz ainda que "as atitudes mágicas diante das imagens são tão poderosas no mundo moderno quanto elas foram nas assim chamadas idades da fé, que, aliás, eram um pouco mais céticas do que imaginamos" (Idem, p. 8). Em um argumento similar ao apresentado por Latour em sua reflexão sobre o Iconoclash e, também, sobre os fe(i)tiches (1996, 2001), Mitchell revisa o papel de uma consciência crítica, supostamente capaz de se livrar de tais atitudes mágicas com relação às imagens que, mesmo nas sociedades ocidentalizadas contemporâneas, podem ser pensadas como se fossem dotadas de vida e capazes de lançar apelos às pessoas que com elas se relacionam. É o que podemos notar na seguinte passagem:
Não há dificuldade, então, de demonstrar que a ideia da personitude das figuras (ou, ao menos, de seu animismo) é táo viva no mundo moderno quanto já foi nas sociedades tradicionais. A dificuldade está em saber o que dizer em seguida. Como as atitudes tradicionais em relação às imagens - idolatria, fetichismo, totemismo - reaparecem as sociedades modernas? Nossa tarefa como críticos culturais está em desmistificar essas imagens, em esmagar os ídolos modernos, em expor os fetiches que escravizam as pessoas? (Mitchell, 2005, p. 32).

Uma reflexão antropológica poderia responder a essas questóes de outra forma, já que precisaria levar em consideração as duas direções da relação ativada por Mitchell. Afinal, será que realmente sabemos o suficiente sobre relaçôes entre imagens e processos de personificação nas ditas sociedades tradicionais, colocadas pelo autor no passado? Até que ponto categorias genéricas como idolatria, fetichismo e totemismo de fato nos auxiliam a compreender, por exemplo, o estatuto da imagem para sociedades da Amazônia ou da Nova Guiné? Se tais categorias não são consensuais e nem suficientes para resumir as particularidades das teorias etnográficas, como pensar a sua passagem para projetos de crítica da cultura e de teorizaçóes sobre a imagem tais como o proposto por Mitchell? A questão não está apenas em dizer que a "personitude" de figuras é reelaborada nas sociedades modernas, mas sim em investigar como ela se faz presente de maneira distinta nestas e em outras sociedades.

Falta algo nessa vontade contemporânea de aproximação com a antropologia: precisamente um conhecimento mais acurado e rigoroso de teorias etnográficas, capazes de projetar uma conexão entre imaginaçôes conceituais distintas e suas respectivas formas de expressão. Esse conhecimento parece ser de fato fundamental para reformular grandes narrativas presentes, mesmo que de modo indireto, em reflexôes sobre arte contemporânea voltadas para a capacidade de pluralização de mundos propiciada pela arte relacional. É o caso do influente estudo de Nicolas Bourriaud, que não deixa de oferecer a seguinte construção temporal em suas especulações: "essa história [do campo relacional], hoje, parece ter tomado 
um novo rumo: depois do campo das relaçóes entre Humanidade e divindade, a seguir entre Humanidade e objeto, a prática artística agora se concentra na esfera das relaçóes inter-humanas [...]" ([1998] 2009, pp. 39-40, itálicos meus). Caberia perguntar o que, nesse passado passe par tout, significariam mais exatamente categorias tais como humanidade e divindade. Quem estaria, mais especificamente, contemplado em tal horizonte genérico anterior? Talvez apenas uma imagem espelhada, mais do que alguma sociedade ou mundo potencialmente pensável para além de certo mecanismo narrativo?

Essas questóes podem ser mais bem compreendidas pelas posiçóes defendidas por uma coletânea recente de artigos dedicada a superar os pressupostos tradicionais do estudo de cultura material na antropologia, propondo uma aliança entre uma perspectiva ontológica e o estudo das "coisas" dos outros. Em Thinking through things, Holbraad, Henare e Wastell (2007, p. 7) postulam "uma metodologia na qual as 'coisas' propriamente ditas podem impor uma pluralidade de ontologias" ou, em outras palavras, "uma metodologia capaz de gerar uma multiplicidade de teorias", e não exatamente a redução de determinado conjunto de fenômenos e/ou de formas expressivas às perspectivas de um axioma teórico previamente elaborado pelo analista. Partindo das reflexóes de Wagner, Strathern e Viveiros de Castro, os autores se alinham com um “construtivismo radical” próximo daquele já proposto por Deleuze e Guattari, ou seja, uma tentativa de imaginar, por meio de um exercício heurístico, a aliança estabelecida entre coisas e conceitos ou, em outros termos, o abandono da distinçáo entre um regime de discurso variável e sua capacidade de determinar um estado de coisas fixo, as things out there a serem explicadas ou interpretadas por alguma posição teórica privilegiada (Idem, p. 13). Dessa forma, coisas (mas também outras formas expressivas) são ou supóem imediatamente uma conexão com determinados critérios especulativos correspondentes que indicam, assim, não apenas uma variação cultural ou epistemológica (variantes internas, portanto, até entẫo perseguidas pela antropologia), mas também uma multiplicação propriamente referencial a ser perseguida pela imaginação etnográfica.

\section{Comparação e tradução}

Mas então não faria mais sentido falar em arte ameríndia, melanésia ou africana, após a revisão do programa da antropologia da arte (e da própria antropologia) por autores como Gow, Descola, Severi, Gell, Strathern e Viveiros de Castro? Teríamos apenas formas expressivas ameríndias, regimes visuais distintos ou coisa similar? Não se trata exatamente de abandonar o termo "arte", tampouco de generalizá-lo via algum projeto teórico (como no caso de Gell) ou via alguma construção comparativa unilateral. $\mathrm{O}$ interesse estaria mais em estabelecer um campo de conexão pela diferença entre distintos pressupostos, analogias e produçóes de sentido, pelo qual categorias como arte ou imagem poderiam ser reinvestidas de sentido; uma conexão comparativa e tradutória, portanto, e não a seleçáo de um determinado conjunto de fenômenos para a satisfação de um ponto de partida predeterminado. Perguntar, por exemplo, pelo estatuto dos objetos e do visível e suas distintas elaboraçóes entre os Yanomami não precisa ser algo motivado pelo desejo de convergência para a arte, como se este fosse um interesse igualmente partilhado por tal sociedade amazônica. A pergunta, além do mais, não deveria ser pretexto para a busca, há tempos já abandonada (Morphy, 1994, pp. 650-651), de categorias tais como "arte" ou "poesia" em outras línguas e configuraçóes ontológicas. O questionamento pode servir, em um primeiro momento, para que nossos pressupostos sobre objetos e imagens (e sua elaboração pela agência artística) consigam ganhar uma perspectiva distinta quando problematizados por outros pressupostos e produçóes possíveis de sentido. Em um segundo momento, tal ampliação de perspectiva conduziria a uma transformação do próprio conhecimento, produzida por uma forma de vínculo que ultrapassa as duas (ou mais) posições postas em relação. Mas como conquistá-lo? Seria para tanto necessário produzir uma prática de conhecimento mais afinada com os dilemas da comparação, tal como encontrados na seguinte passagem de Viveiros de Castro:

Mas a comparabilidade direta não significa necessariamente tradutibilidade imediata, assim como a continuidade ontológica não implica em transparência epistemológica. Como podemos 
restaurar as analogias traçadas por povos amazônicos a partir dos termos de nossas analogias? $\mathrm{O}$ que acontece com as nossas comparaçóes quando as comparamos com as comparaçôes indígenas? (2004, p. 4).

Ao exibir o corpo paramentado, adornado com conchas-valores, a pessoa na Melanésia não é um indivíduo que expressa sua criatividade interna através de uma expressão visual externa (Strathern, 2013). Ela não se constitui por uma exterioridade criativa capaz de singularizá-la, por meio do estilo artístico, como um indivíduo destacado dos demais. As analogias e as comparaçóes almejadas pela pessoa em um ritual de transação de dons transformam-na em uma coisa, especula Marilyn Strathern. Sua coisificação nada tem a ver, no entanto, com a transformaçấo da pessoa em produto de consumo pelas ontologias capitalistas. A pessoa é certamente uma coisa (o conjunto de adornos que perfazem o seu corpo), mas coisas são índices para fluxos de transação entre pessoas. Por isso, a pessoa não se singulariza como indivíduo recoberto por sua máscara de pigmentos, como teria se equivocado o fotógrafo Malcom Kirk em sua série de retratos de nativos da Papua Nova Guiné produzidos nos anos de 1970. Ela faz sentido apenas em conjunto: não como parte de uma totalidade social, que a rigor não existe, mas como uma escala de uma configuração fractal, na qual um e muitos se tornam posiçôes homólogas umas das outras. É por essa razão que, ao recortar e isolar indivíduos contra um pano de fundo neutro, ao transformar e isolar corpos em itens retratísticos, Kirk produzia um equívoco visual por ignorar aquilo que o corpo paramentado tem de mais fundamental na Melanésia: a visualização de relaçóes, a capacidade de fazer com que conexôes sociais se externem através do corpo. O uso do termo "estética" usado por Strathern em The gender of the gift é, a rigor, uma estratégia tradutória para dar conta desse problema, de uma potencial teoria visual da Melanésia (2013, p. 10), ${ }^{11}$ e não de juízos de gosto ou de uma ciência dos princípios da sensibilidade. Trata-se de traduzir a complexa tensão entre ocultamento e manifestaçáo de resultados de relações fundamentais de economias da dádiva na Melanésia, que se tornam visíveis através de proces- sos tais como a produção de uma criança, o cultivo de inhames ou a circulação e exibição de adornos.

Não se esgotam assim tâo facilmente, entretanto, as consequências dessa brevíssima interpolação da teoria etnográfica melanésia com as considerações de Viveiros de Castro sobre as comparaçôes, que apontam para a necessidade de contemplar outros critérios comparativos postos em conexão com os nossos. Mas de que se valem afinal das contas tais critérios? Novamente, de distintos conjuntos de pressupostos, cuja compreensão passa a ser fundamental para a espécie de reflexão antropológica aqui imaginada. Não se pretende, com isso, sustentar uma espécie de criptologia etnográfica, a ser contrastada, como argumento de autoridade, à criptologia conceitual acadêmica. Trata-se, em um primeiro momento, de colocar em contraste distintos léxicos privilegiados por este ou aquele modo de existência, sem os quais não se compreende o próprio estatuto do conhecimento e da expressão. Isso não implica, ademais, em reiterar uma aliança direta entre linguagem e mundo, como já se discutiu ad nauseam desde as críticas ao relativismo linguístico, ainda que o problema da tradução e da variabilidade ontológica siga sendo um desafio corrente para a antropologia (Severi e Hanks, 2014). Termos conceituais isolados, como yochin (pano), utupë (yanomami) ou karon (jê), não podem ser traduzidos diretamente por outros, como "imagem" ou "figuração", sem que se leve em consideração a constelação de outros termos e pressupostos a partir dos quais eles estabelecem sentido; sem que se leve em consideração, mais ainda, suas articulaçôes essenciais com aspectos sensoriais e performativos que extrapolam as próprias categorias da linguagem. Do contrário, poder-se-ia imaginar que o termo empregado por um Marubo para se referir a uma sombra e a uma fotografia (yochin) se traduziria sem muitos problemas pela ideia de "figuração", tendo em vista um suposto universalismo da representação por semelhança. Seria possível sustentar, mais ainda, que tal noção está assentada em uma economia dos objetos destinada à permanência da materialidade capaz de produzir fruição estética, memória e concentração política, o que efetivamente não é o caso das terras baixas sul-americanas (Barcelos Neto, 2008). Além do mais, as categorias 
geralmente associadas ao que se traduz por imagem não possuem exatamente um valor icônico, mas sim indicativo, como bem mostrou Viveiros de Castro (2007) em seu estudo sobre a noção de imagem-espírito entre os Yanomami.

Torna-se, assim, necessário ir além do problema (ainda assim fundamental) de tradução de entidades linguísticas, pois uma reflexão etnográfica envolve certamente controle do léxico conceitual dos dois lados postos em relação (ou seja, de seus potenciais campos semânticos, de suas trajetórias e de suas variaçóes pragmáticas) mas, também, a maneira como tais léxicos se relacionam com pessoas, de como se articulam em relaçóes de socialidade e em produçóes de experiência. O que efetivamente fazem (ou o que se faz de) pessoas nas quais (ou pelas quais) determinados pressupostos são pensáveis? Quais agenciamentos aí se produzem, se vale empregar a noçấo de Deleuze e Guattari? O que efetivamente projeta um mundo no qual categorias como utupë ocupam lugar central? Nas terras baixas da América do Sul, esses agenciamentos preveem a existência de pessoas múltiplas, decorrentes da destruiçáo do indivíduo vivente, que, como no caso do xamanismo yanomami, deve ter seus olhos (sua visão) mortos pela experiência de ingestáo do psicoativo yäkoana (Virola sp.), a fim de que seja adquirido outro sentido proveniente de sua proliferação na multiplicidade infinitesimal das imagens-espírito xapiripë. É isso que se depreende da leitura de trechos de La chute du ciel, de Davi Kopenawa e Bruce Albert. A antropologia especulativa aí desenvolvida é capaz de oferecer tanto os contornos de um outro modo de existência (via um trabalho intenso de mediaçáo tradutória realizado em parceria com Albert) quanto uma compreensão do próprio regime de materialidade e de classificação ocidental. É o que vemos na seguinte passagem, na qual Kopenawa, em uma visita a Paris, reflete sobre o que os brancos chamam de "museu" e sobre o que, afinal das contas, pode ser uma "coisa":

Por fim, por tanto ver as coisas desse museu, terminei por me perguntar se os brancos não haviam já começado a adquirir não apenas os nossos objetos, mas também nós mesmos, os Yanomami, justamente porque estamos em vias de desaparecer. [...] Uma vez mortos, seremos expostos nas caixas de vidro de um museu? [...]. Ao levar [os adornos yanomami] consigo, os brancos capturam também as suas imagens e as guardam muito distante de nossa floresta. É isso que terminará por nos deixar tão feios quanto inábeis na caça (2010, pp. 458-459).

Parece que Kopenawa não se refere exatamente à imagem icônica das coisas, potencialmente retratáveis pelos brancos (Cesarino, 2014, p. 210). A imagem interrompida pelos colecionadores de coisas alheias é, a rigor, outra. Seguindo a sugestão de Viveiros de Castro (2007), ela se referiria antes ao seu aspecto indicativo (seu utupë), a uma espécie de duplo agentivo atrelado a determinadas extensóes corpóreas, capaz de produzir efeitos nos viventes que com elas se relacionam.

Eis algo similar ao que me explicou certa vez um xamã marubo (Cesarino, 2011, pp. 183 ss.), ao dizer como uma determinada coisa, quando extraviada de seu dono, pode causar mal ao extraviador. É que as "coisas", assim como os "bichos" (yoinni) e os humanos visíveis (yora), são, a rigor, compostas por seu aspecto "carcaça" (shakâ) e seu aspecto duplo (vakâ). ${ }^{12}$ Os duplos, assim, podem ser meras réplicas visuais (kayakavi keskáma) ou similares a humanoides (kayakavi keskâ), muitos deles existentes desde os tempos primeiros, tal como os xapiri dos Yanomami. Em ambas as opções serão espécies de imagens-duplo, mas certamente distintas de imagens mentais ou representaçóes subjetivas que compõem as metafísicas modernas. Ao roubar uma determinada coisa, o duplo personificado que a ela se anexa lembra-se de seu dono e envia males (venenos, projéteis invisíveis, falas sopradas) para a pessoa que a retirou de seu lugar de origem, assim fazendo com que ela adoeça. Temos aí, novamente, uma configuração indicativa, pois o duplo não necessariamente se assemelha à sua extensão corporal. Duplos de pássaros, por exemplo, são pessoas que vivem no que concebem para si mesmos como suas casas (ninhos em copas de árvores, por exemplo) e revidam agressóes aos "seus bichos" (awen yoini) ou às "suas carcaças" (awen shakâ) quando agredidos; coisas como equipamentos eletrônicos possuem duplos humanoides similares aos brancos, também capazes de retaliar quando suas extensōes 
corporais são roubadas. É provável que, para os Marubo, a recíproca também seja verdadeira, como parece ser para Kopenawa: as "coisas" anexadas a pessoas (por exemplo, entre os Marubo, são os inaladores de rapé, os adornos de conchas aruá e as próprias casas), quando retiradas dessa conexão, provocam então algum desejo de retaliação por parte de seus duplos. De toda forma, elas deixam de ser componentes de corpos múltiplos para se transformarem em objetos reclassificados pelas categorias do império.

Tratamos, assim, de outros acoplamentos entre pessoas, coisas e imagens, irredutíveis às categorias classificatórias produzidas por um regime de objetificação como o ocidental; um regime que retira as coisas dos outros de sua zona nebulosa, potencialmente ameaçadora, e as objetifica, capturando-as por outras dinâmicas de discurso e de controle (Mitchell, 2005, pp. 145 ss.; Serres apud Latour, 1994, p. 82). Mas como conectar outras formas de acoplamento e seus critérios de comparação aos nossos? Que estatuto de conhecimento poderia ser imaginado a partir daí, uma vez processadas as necessárias críticas à produção, no dizer de Mitchell, dos "maus objetos" do império e suas categorias de contraste (fetichismo, totemismo e idolatria)? Como não se deixar paralisar pela exacerbação de outra crítica, a desencantadora, que, como argumentava Latour (1996, 2001), terminaria por esvaziar toda e qualquer forma de mediação, impedindo assim uma compreensão mais afinada e adensada das formas potenciais de acoplamento e seus desafios ao conhecimento?

\section{Conexão e compatibilização}

O problema da comparação, como postulado por Viveiros de Castro, deve produzir uma transformação radical nos dois lados postos em relação, em vez se constituir por algum ponto de vista externo privilegiado, supostamente capaz de selecionar um determinado conjunto de dados passíveis de serem explicados por suas narrativas ou premissas teóricas. A questão é novamente repensada por Strathern em Partial connections na seguinte frase inspiradora: "a vista de um corpo ao invés da vista de um cume" (the view from a body rather than the view from above) ([1991] 2004, p. 32). Ao se valer do Manifesto Ciborgue de Donna Haraway, Strathern pretendia ir além, por um lado, das perspectivas teóricas comparativas produzidas por um ponto de vista de Sirius e, por outro, da condenação de toda forma de perspectiva pela antropologia pós-moderna. Diluir qualquer possibilidade de constituição de uma posição produtora de conhecimento em uma rede polifônica, marcada pelo descentramento radical produzido pela destruiçáo da autoridade narrativa, implicaria em cometer um suicídio epistemológico característico do pensamento pós-moderno e pós-colonial. Reiterar a posição do sujeito autocentrado, por outro lado, implicaria em remendar a clássica posição moderna de autoridade produtora de grandes narrativas, ainda em voga no pensamento contemporâneo. A alternativa, para Strathern, estaria na metáfora do Ciborgue, que produz seu centro por meio de uma corporalidade híbrida, constituída por compatibilidades entre capacidades distintas, e não pelo isolamento e privilégio comparativo. Torna-se assim possível imaginar uma corporalidade que nada tem a ver com as cisóes entre interior e exterior, mas sim com um estado alternativo de experiência produzido por acoplamentos entre complexidades. Compatibilidade e não comparabilidade, portanto, seria o desafio em questão; constituiçâo de um corpo conectivo como modo de afetação entre configuraçôes de mundo distintas e suas distintas produçôes de sentido.

Mas, ainda assim, como essa imagem da corporalidade conectiva se relacionaria com o problema mais específico de compreensão de outros regimes ontológicos e suas respectivas formas expressivas? No final de Partial connections, Strathern sugere que a pessoa na Melanésia poderia ser compreendida como uma espécie de Ciborgue: a pessoa náo se encerra em uma totalidade ou em indivíduos; seus limites são compostos pelas conexôes entre corpos que se singularizam em posições marcadas por acoplamentos e extensóes transespecíficas (inhames como agentes sociais, exibidos e paramentados como manifestaçóes de relaçóes, por exemplo). Não seria inoportuno empregar tal recurso heurístico para a compreensão de outras formas de complexidade, produzidas, por exemplo, na Amazônia. Noções de corpo-dono como yora, entre 
os Marubo (Cesarino, 2011), e warah-, entre os Kanamari (Costa, 2010), também são compostas por homologias escalares e extensóes transespecíficas, mas com base em dilemas ontológicos distintos daqueles que caracterizam a pessoa melanésia. No final, essas noçóes revelam um rendimento da complexidade irredutível às produçóes de modelos teóricos comparativos e grandes narrativas explicativas. O que isso quer dizer mais especificamente? Que a compreensão do problema da pessoa e do corpo entre os Marubo (e com isso entenda-se a sua extensão em padrôes gráficos, parafernálias rituais como inaladores de rapé e cajados, além de sua extensão em uma rede de outros corpos produzidos pelo parentesco e passíveis de ultrapassar o que os modernos entendem por "humano") agencia uma complexidade irredutível a modelos explicativos baseados em premissas ecológicas, cognitivas, estéticas, sociológicas ou linguísticas. Ela certamente necessita dessas premissas para sua compreensão, mas também de outras potencialmente envolvidas e, sobretudo, daquelas postuladas pelos próprios Marubo, Kanamari ou Yanomami.

O panorama produzido por essa constatação é certamente vertiginoso, como na imagem da Poeira de Cantor empregada por Strathern em Partial connections para tratar de um dilema similar - o da estreiteza de perspectiva teórica das etnografias da Melanésia. Mas ele indica, também, uma maneira de fazer com que o conhecimento etnográfico adquira a densidade necessária e merecedora da compreensão das formas alheias de produção de sentido. Essa perspectiva revela, em suma, que a compreensão tradutória das redes de categorias conceituais nativas e suas respectivas expressóes não tem propriamente uma solução final, não se detém nesta ou naquela generalização teórica (Quimeras capazes de produzir e movimentar o conhecimento tradicional? Índices passíveis de desencadear abduçóes e suas respectivas relações sociais? Sim, talvez, mas o que mais?). O problema demanda, antes, um exercício perpétuo de pensamento, de variação ou de ensaio em torno das ramificaçóes produzidas pelos acoplamentos de complexidades, cujos caminhos são ainda bastante desconhecidos pela etnologia. $\mathrm{O}$ conhecimento etnográfico seria, então, aquele que se produz a partir de um corpo, e não de um ponto de vista distanciado, superior ou privilegiado. Um corpo estabelecido na zona de interconexão entre imaginaçóes distintas, mas náo da projeçáo ou da pressuposiçáo de uma totalidade. Trata-se, então, da capacidade de produzir uma zona de complexidade que pode ser motivada por formas distintas de expressão pela imagem, pela palavra ou pela materialidade. Essa produção seria então dependente do trabalho de ontografia, fundamental para que se estabeleça um vínculo imaginativo com outros regimes de conhecimento e de expressão. É isso que produzirá efeitos em um campo de reflexão que, talvez, não seja mais propriamente nosso ou dos outros, mas sim constituído pela conexão entre distintas capacidades.

\section{Notas}

1 Entre os títulos mais recentes sobre o assunto, ver Layton (1981) para um estudo geral; Morphy (1994) para uma revisão sucinta; Morphy e Perkins (2006) para uma seleção dos principais textos de referência; Coote e Shelton (1992) para uma coletânea de artigos; Pinney e Thomas (2001) para outra coletânea dedicada a absorver o pensamento de Alfred Gell.

2 Para um estudo sobre a coleção e o pensamento de Pitt-Rivers, ver Chapman (1985).

3 Price (1989) realiza uma reflexão crítica sobre a expedição Dakar-Djibouti.

4 A esse respeito, ver Jacknis (1985).

5 Ver Lévi-Strauss (1986, pp. 341 ss.).

6 James Clifford (1988) oferece uma revisão crítica da polêmica exposição Primitivism in the 20th Century Art. Desde então, outras tantas exposiçôes, como a Animism (Antuérpia, 2010), a Histoires de Voir (Fondation Cartier, Paris, 2012) e a Documenta 13, têm retomado as discussóes sobre a relação entre antropologia, artes visuais e artes não ocidentais. $\mathrm{O}$ crítico e curador brasileiro Moacir dos Anjos (2005) faz uma breve síntese de algumas dessas exposições, que mereceriam um estudo à parte, dedicado, também, a outros projetos brasileiros, como as exposiçóes Histórias Mestiças (2014), Panorama da Arte Contemporânea Brasileira (2015) e 32a Bienal de São Paulo (2016).

7 Neste artigo, são minhas todas as traduçôes de citaçôes que constem em língua estrangeira na bibliografia.

8 A noção de Kunstwöllen, cuja tradução é disputada por especialistas (ver por exemplo o estudo introdutório de Otto Pächt a uma edição francesa de Riegl 
[1978]), se mostrava influente no clássico Primitive art de Franz Boas, de 1927, para quem a vontade de produzir um resultado estético era fundamental para a compreensão da estabilidade formal e do estilo (Boas ([1927] 1955, pp. 11-12).

9 Diferentes exemplos de abordagens marcadas pela semiologia podem ser encontrados em Munn (1973), Geertz (1980, 1983), em diversos artigos reunidos em Forge (1973), em Vidal (1992) e Ribeiro (1987), entre outros. A semiologia como paradigma dominante para o estudo da arte e da imagem tem sido questionada não apenas por Gell, mas por outros tantos autores como Debray (1992), Cauquelin (2007), Belting (2011) e Mitchell (1994).

10 Semelhante estrutura argumentativa, aliás, foi muito bem desmontada por Latour (1991) e Viveiros de Castro (2002), que encaminham alternativas epistemológicas para as soluçôes tradicionais do relativismo de base universalista, marcados pela pressuposição de uma natureza ou realidade para a qual converge a multiplicidade de culturas ou de crenças.

11 É importante atentar para o uso heurístico da noção de "teoria" em Strathern, como se percebe na seguinte passagem: "Ainda assim, o que andei dizendo realmente indica uma teoria visual indígena? Quais seriam os seus elementos? Eles não precisam, evidentemente, de uma teoria [...]. Na realidade, a questáo é uma maneira de formular o que o antropólogo euroamericano precisa construir como uma teoria para descrever esses artefatos, assim servindo de contraponto para o que ele ou ela, náo fosse por isto, poderia tomar por pressuposto. [...] O que estou atribuindo às práticas da Papua Nova Guiné integra uma tentativa de me fazer (de nos fazer) 'ver' de maneira diferente. [...] Em outras palavras [...]. não se trata exatamente de dizer que o mundo construído por essas conferências é o mundo que os Melanésios veem (esses artefatos não são dedicados para a descrição de 'um mundo'). É que, sem essa construção, 'nosso' mundo (no qual nós estamos implicados) será tudo o que 'nós' vemos" (2013, p. 145)

12 "Coisa" é o termo que emprego na falta de outro melhor, pois, em marubo, awe não se refere exatamente ao problema filosófico das substâncias ou "coisas lá fora" (objectus, algo posto diante do sujeito) mas sim ao conjunto de (coisas?) acopladas à pessoa (noken awe, "as nossas coisas", portanto, em uma tradução aproximada) e que a define como configuraçáo prototípica de parentesco.

\section{BIBLIOGRAFIA}

ALMEIDA, Mauro William Barbosa de. (2013), "Caipora e outros conflitos ontológicos".R@u, 5 (1): 7-28.

BARCELOS NETO, Aristóteles. (2008), "Choses (in)visibles et (im)périssables: temporalité et materialité des objets rituels dans les Andes et en Amazonie". Gradhiva, 8: 112-129.

BELTING, Hans. ([2001] 2011), An anthropology of images. Princeton, Princeton University Press.

BOAS, Franz. ([1927] 1955), Primitive art. Nova York, Dover Publications.

BOURRIAUD, Nicolas. ([1998] 2009), Estética relacional. São Paulo, Martins Fontes.

BRAUN, Barbara. (1993), Pre-Columbian art and the post-Columbian world: ancient American sources of modern art. Nova York, Harry N. Abrams Publishing.

CAUQUELIN, Anne. (2007), Les théories de l'art. Paris, PUF.

CESARINO, Pedro de Niemeyer. (2011), Oniska: poética do xamanismo na Amazônia. São Paulo, Perspectiva/Fapesp.

. (2014), "Ontological conflicts and shamanistic speculations in Davi Kopenawa's The falling sky". HAU - Journal of Ethnographic Theory, 4: 289-295.

CLIFFORD, James. (1988), The predicament of culture. Cambridge, Harvard University Press.

CHAPMAN, William. (1985), "Arranging ethnology: A. H. L. F. Pitt-Rivers and the typological tradition", in G. Stocking Jr. (org.), Objects and others: essays on museums and material culture. Madison, The University of Winscosin Press, pp. 15-49.

COOTE, Jeremy \& SHELTON, Anthony (eds.). (1992), Anthropology, art and aesthetics. Oxford, Clarendon Press.

COSTA, Luiz Antonio Lino da Silva. (2010), "The Kanamari body-owner: predation and feeding in western Amazonia”. Journal de la Société des Américanistes, 96 (1): 169-192.

DEBRAY, Régis. (1992), Vie et mort de l'image. Paris, Gallimard. 
DÉLÉAGE, Pierre. (2011), "Les pictographies narratives amérindiennes", in Ch. Jacob (ed.), Lieux de savoir 2: les mains de l'intellect. Paris, Albin Michel, pp. 744-764.

DE L'ESTOILE, Benoît. (2007), Le gôut des autres: de l'exposition coloniale aux arts premiers. Paris, Flammarion.

DESCOLA, Philippe. (2005), Par-delà nature et culture. Paris, Gallimard.

(2010), "L'envers du visible: ontologie et iconologie", in A-C Taylor e Th. Dufrêne (eds.), Cannibalismes disciplinaires: quand l'histoire de l'art et l'anthropologie se rencontrent. Paris, Musée du quai Branly/INHA, pp. 25-37.

DIDI-HUBERMAN, Georges. (2002), Limage survivante: histoire de l'art et temps des fantômes selon Aby Warburg. Paris, Les Éditions de Minuit.

DOS ANJOS, Moacir. (2005), Local/global: arte em trânsito. Rio de Janeiro, Zahar.

DUFRÊNE, Thierry. (2012), "Art contemporain et anthropologie". Anais do XXXII Colóquio CBHA. Universidade de Brasília, Comitê Brasileiro de História da Arte.

FORGE, Anthony (ed.). (1973), Primitive art and society. Londres/Nova York, Oxford University Press.

FOSTER, Hal. (1996), The return of the real. Cambridge, MIT Press.

GEERTZ, Clifford. (1980), Negara: the theatre state in 19th Century Bali. Princeton, Princeton University Press. (1983), Local knowledge. Nova York, Basic Books.

GELL, Alfred. 1993. Wrapping in images: tattoing in Polynesia. Oxford, Clarendon Press.

. (1998), Art and agency. Oxford, Clarendon Press.

. (1999), The art of anthropology. Londres, Athlone.

HOLBRAAD, Martin. (2003), "Estimando a necessidade: os oráculos de Ifá e a verdade em Havana”. Mana - Estudos de Antropologia Social, 9 (2): 39-77.

HOLBRAAD, Martin; HENARE, Amiria \& Wastell, Sari. (2007), Thinking through things: theorising artefacts ethnographically. Londres, Routledge.
INGOLD, Tim (ed.). (1994), Key debates in anthropology. Londres, Routledge.

JACKNIS, Ira. (1985), "Fanz Boas and exhibits: on the limitations of the museum method of anthropology", in G. Stocking Jr. (org.), Objects and others: essays on museums and material culture. Madison, The University of Winscosin Press, pp. 75-112.

KOPENAWA, Davi Yanomami \& ALBERT, Bruce. (2010), La chute du ciel: paroles d'un chaman yanomami. Paris, Plon.

KROEBER, Alfred. (1949), "Art", in J. Steward (ed.), Handbook of South American Indians 5. Washington, Smithsonian Institution, Bureau of American Ethnology, pp. 411-492.

KÜCHLER, Suzanne. (2002), Malanggan: art, memory and sacrifice. Oxford, Berg.

LÉVI-STRAUSS, Claude. (1986), O olhar distanciado. Lisboa, Ediçóes 70 (ed. fr. 1983, Le regard éloigné, Paris, Plon).

LAFUENTE, Pablo. (2013), “Magiciens de la terre' and the development of transnational project-based curating", in L. Seeds (ed.), Making art global. Part 2: Magiciens de la terre 1989. Londres, Afterall, pp. 8-24 (col. Exhibition histories).

LATOUR, Bruno. (1994), Jamais fomos modernos. São Paulo, Editora 34 (ed. francesa: Nous n'avons jamais été modernes, Paris, La Découverte, 1991).

. (1996), Petite réflexion sur le culte moderne des dieux faitiches. Paris, Synthélabo.

. (2001), "What is iconoclash? Or is there a world beyond the image wars?", in $\mathrm{B}$. Latour e P. Weibel (orgs.), Iconoclash, Cambridge, ZKM/MIT Press, pp. 14-37.

(2007), Reassembling the social. Oxford, Oxford University Press.

LAYTON, Robert. (1981), The anthropology of art. Nova York, Columbia University Press.

LEACH, James. (2007), "Differentiation and encompassement: a critique of Alfred Gell's theory of the abduction of creativity", in M. Holbraad et al. (eds.), Thinking through things, Londres, Routledge, pp. 167-189.

MITCHELL, W. J. T. (2005), What do pictures want? Chicago, The University of Chicago Press. 
. (1994), Picture theory. Chicago, The University of Chicago Press.

MORPHY, Howard. (1994), "The anthropology of art", in T. Ingold (ed.), Companion encyclopaedia of anthropology, Londres/Nova York, Routledge, pp. 648-685.

\& PERKINS, Morgan. (2006), The anthropology of art: a reader, Oxford, Blackwell.

MUNN, Nancy. (1973), Walbiri iconography. Chicago, The University of Chicago Press.

PINNEY, Christopher \& THOMAS, Nicholas. (2001), Beyond aesthetics: art and the technologies of enchantment. Oxford, Berg.

PRICE, Sally. (1989), Primitive art in civilized places. Chicago, The University of Chicago Press.

RIBEIRO, Berta (coord.). (1987), Suma etnológica brasileira. Vol. 3: Arte indígena. Petrópolis, Vozes.

RIEGL, Aloïs. (1978), Grammaire historique des arts plastiques. Paris, Éditions Klincksieck.

SAHLINS, Marshall. (1981), Historical metaphors and mythical realities. Ann Arbor, The University of Michigan Press.

. (1985), Islands of history. Chicago, The University of Chicago Press.

SEVERI, Carlo. (2007), Le principe de la chimère. Paris, Rue d'Ulm/Musée du quai Branly. \& HANKS, William. (2014), "Translating worlds: the epistemological space of translation". HAU - Journal of Ethnographic Theory, 4 (2): 1-16.

STRATHERN, Marilyn. (1986), The gender of the gift. Berkeley, University of California Press.

. ([1991] 2004), Partial connections.

Oxford, Altamira Press.

STRATHERN, Marilyn. (2013), Learning to see in Melanesia. Manchester, $H A U$ - Journal of Ethnographic Theory (Masterclass Series, vol. 2).

THOMAS, Nicholas \& PINNEY, Christopher. (2001), Beyond aesthetics: art and the technologies of enchantment. Oxford, Berg.

VIDAL, Lux (org). (1992), Grafismo indígena. São Paulo, Edusp/Studio Nobel.

VIVEIROS DE CASTRO, Eduardo. (2002), "O nativo relativo". Mana, 8 (1): 113-148.
(2004), "Perspectival anthropology and the method of controlled equivocation". Tipiti, $2(2)$.

. (2007), "The crystal forest: notes on the ontology of Amazonian spirits". Inner Asia, 9: 153-172. PUF.

WAGNER, Roy. (1981), The invention of culture. Chicago, University of Chicago Press.

WARBURG, Aby. (2003), Le rituel du serpent. Paris, Macula. 


\section{CONFLITOS DE PRESSUPOSTOS NA ANTROPOLOGIA DA ARTE: EM TORNO DE PESSOAS, COISAS E IMAGENS}

\section{Pedro Cesarino}

Palavras-chave: Arte; Antropologia; Objeto; Imagem; Comparação.

O artigo propóe uma revisão crítica de estudos antropológicos da arte e de estudos selecionados de arte relacionados à antropologia. Recuperando aspectos fundamentais dos modos de compreensão e categorização de formas expressivas não ocidentais, busca-se apontar para a persistência de determinados pressupostos ontológicos (tais como a centralidade do objeto e do indivíduo criador) e seus entraves para o entendimento de complexidades etnográficas não modernas. Pretende-se, por fim, oferecer alternativas para uma reflexão sobre formas expressivas diversas que escape dos entraves gerados pela categoria "arte", valendo-se de perspectivas recentes sobre o problema da comparação e da tradução na antropologia.
CONFLICTS OF

PRESUPPOSITIONS IN THE

ANTHROPOLOGY OF ART: PERSONS, THINGS AND IMAGES

Pedro Cesarino

Keywords: Art; Anthropology; Object; Image; Comparison.

This article proposes a critical revision of the anthropological studies on art as well as of selected art studies related to anthropology. Recovering key aspects of Western categorizations of non-western expressive forms, this article maps the persistence of ontological presuppositions (such as the notion of object and of the individual creator) that hinders the understanding of ethnographic complexities. This study also aims to offer alternatives to a reflection on other people's expressive forms that goes beyond the notion of art, taking into account recent anthropological reflections on the problems of comparison and translation.

\section{CONFLITS D'HYPOTHÈSES EN ANTHROPOLOGIE DE L'ART: AUTOUR DES PERSONNES, DES CHOSES ET DES IMAGES}

\section{Pedro Cesarino}

Mots clés: Art; Anthropologie; Objet; Image; Comparaison.

L'article propose une révision critique d'études anthropologiques de l'art et d'études sélectionnées de l'art liées à l'anthropologie. Tout en récupérant des aspects fondamentaux des modes de compréhension et de classification des formes expressives non-occidentales, nous voulons indiquer la persistance de certaines hypothèses ontologiques (telles que la centralité de l'objet et de l'individu créateur) et de ces obstacles à la compréhension des complexités ethnographiques non modernes. Nous tentons également de proposer des alternatives pour une réflexion sur les diverses formes expressives qui s'échappent des obstacles générés par la catégorie " art ", à l'aide de perspectives récentes sur le problème de la comparaison et de la traduction en anthropologie. 